STUDI

FRANCESI

\section{Studi Francesi}

Rivista quadrimestrale fondata da Franco Simone

165 (LV | III) | 2011

LA RAPPRESENTAZIONE DELLA MADRE NELLA

LETTERATURA FRANCESE DEL NOVECENTO a cura di Dario Cecchetti e Michele Mastroianni

\title{
Barbey d'Aurevilly en tous les genres, Actes du Colloque réunis par Brigitte Diaz
}

\section{Maria Emanuela Raffi}

\section{OpenEdition \\ Journals}

\section{Edizione digitale}

URL: http://journals.openedition.org/studifrancesi/5082

DOI: ERREUR PDO dans /localdata/www-bin/Core/Core/Db/Db.class.php L.34 : SQLSTATE[HY000]

[2006] MySQL server has gone away

ISSN: 2421-5856

\section{Editore}

Rosenberg \& Sellier

\section{Edizione cartacea}

Data di pubblicazione: 1 décembre 2011

Paginazione: 663-664

ISSN: 0039-2944

\section{Notizia bibliografica digitale}

Maria Emanuela Raffi, «Barbey d'Aurevilly en tous les genres, Actes du Colloque réunis par Brigitte Diaz», Studi Francesi [Online], 165 (LV | III) | 2011, online dal 30 novembre 2015, consultato il 08 janvier 2021. URL: http://journals.openedition.org/studifrancesi/5082 ; DOI: https://doi.org/ERREUR PDO dans / localdata/www-bin/Core/Core/Db/Db.class.php L.34 : SQLSTATE[HY000] [2006] MySQL server has gone away

Questo documento è stato generato automaticamente il 8 janvier 2021.

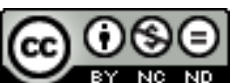

Studi Francesi è distribuita con Licenza Creative Commons Attribuzione - Non commerciale - Non opere derivate 4.0 Internazionale. 


\title{
Barbey d'Aurevilly en tous les genres, Actes du Colloque réunis par Brigitte Diaz
}

\author{
Maria Emanuela Raffi
}

\section{NOTIZIA}

Barbey d'Aurevilly en tous les genres, Actes du Colloque tenu à l'Université de Caen, SaintSauveur-le Vicomte et Valognes (16-18 octobre 2008) réunis par Brigitte DIAZ, Presses Universitaires de Caen, 2011, pp. 256.

1 Nell'«Avant-propos», che introduce ai sedici contributi del Convegno, Brigitte DIAZ sottolinea la varietà dei generi letterari praticati da Barbey d'Aurevilly, raggruppandoli in tre grandi aree: «la sphère de l'intime et de l'écriture privée; le domaine public et journalistique du critique; le territoire plus vaste de l'œuvre littéraire».

La prima parte, «Barbey d'Aurevilly Ex Imo», dedicata alla scrittura intima, si apre con uno studio di Françoise SIMONET-TENANT sulla natura e l'interazione dei vari scritti privati dell'autore, dai Memoranda, destinati a tre «lecteurs intimes» privilegiati - Trebutien, Saint-Victor e Paul Quemper -, alle lettere che fanno loro quasi da eco, tutti in stretta connessione con il Cahier vert di Maurice de Guérin (Barbey d'Aurevilly: lire, écrire, éditer des journaux intimes).

3 Ai due primi Memoranda è dedicato il contributo di Roland LE HUENEN (Mélancolie de Barbey d'Aurevilly: les deux premiers "Memoranda"), che sottolinea il carattere quotidiano e insignificante delle annotazioni, la noia che le pervade e, soprattutto, la malinconia che ne consegue, che Barbey cerca di combattere con rimedi fisici e morali.

4 La scrittura epistolare e la letteratura non convivono pacificamente nella scrittura di Barbey d'Aurevilly; è ciò che mostra lo studio di Brigitte DIAZ, Barbey d'Aurevilly épistolier: la lettre contre le livre, approfondendo la convinzione dello scrittore che la corrispondenza sia fondata su una 'verità' negata alla letteratura e ne costituisca un 
importantissimo complemento, che la trascina da un lato verso l'esercizio sempre rimpianto della conversazione e dall'altro verso la concreta pratica della 'grafia'.

$5 \quad$ In Effets de spectres: pour une poétique de la ville morte chez Jules Barbey d'Aurevilly Pascale AURAIX-JONCHIÈRE analizza un frammento di diario relativo ad un ritorno dello scrittore a Saint-Sauveur, accostandolo alla poesia «À Valogne» - altra piccola città di provincia «sèche et grise» - che con il suo significativo «Ex imo» in epigrafe attraversa l'opera di Barbey consacrando il ruolo fondamentale che in essa gioca la «trace mémorielle».

6 «Histoire, récit, roman», seconda parte del volume, presenta anzitutto il contributo di Gérard GENGEMBRE, Roman et contre-révolution chez Barbey d'Aurevilly, che mette a fuoco la relazione della scrittura narrativa di Barbey con la storia e in particolare con la Rivoluzione, incarnazione del male in quanto violenta rottura dell'ordine divino, contro la quale i romanzi di Barbey si ergono come una sorta di epopea contro-rivoluzionaria.

7 La couleur du temps di Aude DÉRUELLE presenta un altro punto di vista sul rapporto dei romanzi di Barbey con la storia, attraverso il concetto di «déshistoricisation du temps»; la presa sulla storia avviene attraverso un'immagine e soprattutto attraverso un colore, ma senza diventare descrizione o cedere al «pittoresque romantique», in continua tensione «entre une immanence rêvée et une transcendance impérieuse».

Alla «période rhétorique» di Barbey d'Aurevilly, tutta squilibrata nello sviluppo considerevole della protasi rispetto ad un'apodosi «lapidaire», è dedicato lo studio di Éric BORDAS, Le souffle du conteur, che illustra, analizzando alcuni passi di testi aurevilliani, le strategie stilistiche utilizzate per realizzare il particolare «souffle oratoire», la specifica «dramatisation énonciative» che ne fondano e ne caratterizzano il ritmo.

9 A «Barbey d'Aurevilly critique» è dedicata la terza parte del volume, a partire dal saggio di José-Luis DIAZ su Le "Stator" et l'"Intense": Barbey d'Aurevilly face à la Babel critique. Partendo dalla netta stroncatura dei critici contemporanei che Barbey ha sempre espresso in nome di un'immagine idealizzata del critico - giudice implacabile e austero, ma al tempo stesso appassionato e ardito - Diaz legge la critica di Barbey come azione e movimento, in cui elementi fondamentali appaiono «l'aperçu, l'émotion, l'accent».

10 In La théorie en acte: les préfaces 'in texte' des "Diaboliques", stéphanie TRAVER prende in esame due "préfaces internes» presenti nella raccolta Les Diaboliques, in «Dessous de cartes d'une partie de whist» e «La vengeance d'une femme». Entrambe rivelano aspetti significativi della concezione aurevilliana del romanzo: «l'esthétisation du réel et sa perception par un acteur particulier» per il primo testo, «la confrontation polémique $[\mathrm{du}]$ discours social et $[\mathrm{du}]$ discours autorial» per il secondo.

11 Barbey d'Aurevilly critico entusiasta e appassionato del Grand Siècle, con una solida formazione letteraria classica - benché ostile ad ogni forma di erudizione -, favorevole al recupero editoriale di testi di interesse storico/politico come l'opera di Saint-Simon o di La Bruyère, ma assolutamente contrario al recupero di autori segnati dalla «galanterie», è il ritratto che Marie-Gabrielle LALLEMAND presenta in Oubliés et inconnus du XVII ${ }^{e}$ siècle jugés par Barbey d'Aurevilly.

12 Tre soltanto sono le poetesse sue contemporanee cui Barbey d'Aurevilly ha dedicato uno scritto: Marceline Desbordes-Valmore, Delphine de Girardin e Louise Ackerman; secondo christine PLANTÉ («Une poète, cette chose si rare»; Barbey d'Aurevilly critique des femmes poètes) Barbey mostra della considerazione solo per il legame fra donna e poesia, 
mentre le scrittrici in prosa sono incluse fra «les bas-bleus», sintomo, queste ultime, della degenerazione politica indotta dalla democrazia.

In «À la frontière des genres», quarta parte del volume, sono presentati tre contributi. Il primo, Du dandysme et de George Brummel: d'un genre à l'autre di catherine BOSCHIANCAMPANER, prende in esame il saggio di Barbey sul dandysme nel quale emerge, oltre al sentimento di «une vanité exacerbée» - particolarmente marcato nell'«histoire de la princesse»-, anche una componente ermafrodita, resa più esplicita dall'espressione usata dall'autore per il protagonista del saggio in questione: «exemplum ut talpa».

Il dandysme è l'oggetto anche del saggio di David COCKSEY, Aux basques d'un genre oublié: Barbey d'Aurevilly et le dandysme littéraire, che si propone di definire lo specifico dandismo aurevilliano, tiraillé fra l'identificazione al personaggio di Brummel e una presa di distanze volta a salvaguardare per lo scrittore un «ethos» meno superficialmente riconoscibile e insieme il convergere di scrittura e dandismo come comune «transposition du domaine de la matière à celui de l'esprit».

Le théâtre de la mémoire dans l'œuvre aurevillienne di sophie LUCET approfondisce l'ipotesi secondo la quale Une page d'histoire costituirebbe una «mise en abîme» dell'opera di Barbey e una sorta di manifesto artistico dell'autore, in cui la storia non viene raccontata attraverso «des noms écrits dans le dictionnaire de la gloire», ma 'messa in scena' dai protagonisti di una vicenda appassionata in una sorta di teatro della memoria.

16 In «Lieux de mémoire aurevilliens», ultima sezione della raccolta, stéphane LAîné prende in esame gli inserimenti di patois normanno introdotti da Barbey nei romanzi L'Ensorcelée, Une vieille maîtresse, Un prêtre marié e Le Chevalier des Touches e il dibattito polemico che ha accompagnato questa scelta, passando poi ad uno studio dettagliato delle forme dialettali utilizzate (Les normandismes de Barbey d'Aurevilly).

17 Nel contributo successivo, Lieux de mémoire aurevilliens: le cas du musée de Saint-Sauveurle-Vicomte, che chiude il volume, Mélanie LEROY-TERQUEM espone le vicende dei «lieux de mémoire aurévilliens», progressivamente migrati da Parigi alla Normandia, e la storia particolare del musée Barbey d'Aurevilly, ricostituito dopo i bombardamenti della seconda guerra mondiale e inaugurato nel 1956 in alcune parti restaurate del Château de Saint-Sauveur. 